\title{
LETTERS/ERRATA
}

P K Sarkar, M Obstet Gynae, FRCOG

Consultant Gynaecologist, Edith Watson Unit, Burnley General Hospital, Casterton Avenue, Burnley BB10 2PQ, UK

References

Anderson J, Gunn E, Hunter M, Owen P. Documentation of preoperative counselling for sterilisation : a complete cycle.

Royal College Obstetricians and Gynaecologists Evidence-Based Clinical Guideline No. 4). London, UK: RCOG Press, 2004

Yunus D, Sarkar PK. Re-audit on medical record keeping in female sterilization. East Lancashire Hospitals NHS Trust, June 2005.

4 James James CE. Medico-legal aspects of obstetrics and gynaecology. In: Stud J (ed.), The Yearbook of the Royal College of Obstetricians and Gynaecologists. London, UK: RCOG Press, 1955; Chapter 7. Edozien L. Counselling for female sterilisation. Br J Fam
Plann 1997; 23: 14-15.

\section{Effective copper surface area of \\ IUDs}

Many providers of intrauterine devices (IUDs) wrongly believe that the nominal surface area of copper IUDs equals the effective copper surface area. The reality is different, however. This letter explains the situation.

Studies suggest that a good contraceptive efficacy is obtained with IUDs having a copper surface area of $200 \mathrm{~mm}^{2}$. Failure rates of the $\mathrm{T}$-Safe ${ }^{\circledR} \mathrm{TCu} 200$ are of the order of 3.0 at 2 years. When the copper surface area is increased to 380 $\mathrm{mm}^{2}$, failure rates are usually less than 1.5 at 2 years. No additional reduction in failure rate is seen when the copper surface area is increased further.

These clinical studies were conducted with copper IUDs provided with a copper wire wound around the stem of the IUD. It is important to distinguish between IUDs with copper wire and the ones that have copper sleeves or a combination of the two. The remark by Kosonen is important: "Only in the case of sleeves is the nominal and the effective surface area the same. When copper wire is used, that part of the wire lying against the plastic body is ineffective and should not be calculated as a part of the effective surface area".1 Other researchers confirm these findings: "The portions of the wire winding in contact with the plastic surface give off hardly any copper". 2 Chantler writes: "It has been shown that there is negligible corrosion of the copper in contact with the plastic core and that this area should be discounted in the calculation of the active surface area of the copper". 3 The effective copper surface area of the TCu200 IUD is only $120 \mathrm{~mm}^{2}$ and of the T-safe ${ }^{\circledR} \mathrm{TCu} 380 \mathrm{~A}$ IUD $252 \mathrm{~mm}^{2}$ (Figure 1). This research also showed that copper release is lower the more the winding of the copper wire is tighter. This is the case with high-load copper IUDs such as Multiload ${ }^{\circledR}$ Cu375 and TCu380A. One could

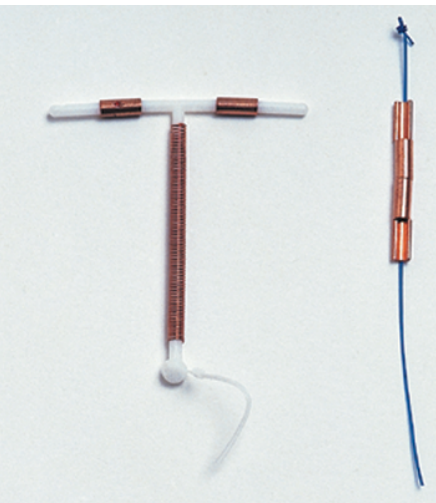

Figure
(right)

conclude that $40 \%$ of the copper wire is 'ineffective'.

With the frameless GyneFix ${ }^{\circledR}$ IUD, all surface areas are exposed to the uterine environment. This is a fundamental difference compared to conventional IUDs. Copper-release studies with the standard GyneFix $330^{\circledR}$ IUD removed after more than 10 years of use have shown that the copper surface area decreases very little over that period, only $7 \%$ after 12 years of use (Contrel, manufacturer's data on file). This could explain the high efficacy of the small GyneFix ${ }^{\circledR} 200$ IUD (Figure 1), less than 1.0 at 3 years of use, ${ }^{4}$ and the absence of increase in annual pregnancy rate with GyneFix as the surface area of the GyneFix IUD decreases very little over time. The copper content of the GyneFix 200 is $280 \mathrm{mg}$, which is higher than the copper content of TCu380A (244.7 mg of copper) having a lifespan of at least 10 years.

The smaller the size of the GyneFix the less the effect on menstrual blood loss. Women wearing the small GyneFix 200 IUD report a similar bleeding pattern when compared with the bleeding pattern before insertion of the IUD. ${ }^{5}$ At the same time, the small surface area optimises tolerance. This could be important since abnormal bleeding and pain are the two major reasons for IUD discontinuation.

Dirk Wildemeersch, MD

Medical Director, Contrel Research, Ghent, Belgium.E-mail:dirk.wildemeersch@contrel.be

ement on competing interests

Dirk Wildemeersch is a Belgian gynaecologist and Medical Director of Contrel Research, a company which was established to manage clinical research and to develop and study innovative drug delivery technologies, aimed at finding improved methods for prevention and treatment of gynaecological conditions. improvements to birth control methods, and higher levels of safety, user acceptability, compliance and quality of life for and FibroPlant ${ }^{\mathbb{B}}$ IUDs.
1 Kosonen A Corrosion of copper in utero. In: Hafez ESE,

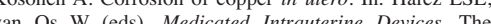
Hage The Netherlands: Martinus Nijhoff, 1980; 22 . 29. Wagner $\mathrm{H}$. Intrauterine contaction past pesent and Wagner H. Intrauterine contraception: past present and
future. In: Rabe T, Runnebaum B (eds), Fertility Control: Update and Trends. Berlin, Germany: Springer, 1999; 151-171.

Chantler EN. Copper loss from copper IUDs. In: Zatuchni GI, Goldsmith A, Sciarra JJ (eds), Intrauterine Contraception: Advances and Future Prospects. Philadelphia, PA: Harper \& Row, 1984; 198-210. Cao X, Zhang W, Zhao X, Lin N, Wang L, Li C, et al. Threeyear efficacy and acceptability of the GyneFix ${ }^{\circledR} 200$ intrauterine system (IUS). Contraception 2004; 69: $207-211$.

Wildemeersch D, Rowe PJ. Assessment of menstrual blood loss in Belgian users of the frameless copper-releasing IUD with copper surface area of $200 \mathrm{~mm}^{2}$ and users of a copperevonorgestrel-releasing intrauterine system. Contraception 2004; 70: 169-172

\section{Inappropriate advertising?}

I was shocked to see the Emotional Bliss advertisement in the last issue of the Journal $(J$ Fam Plann Reprod Health Care 2005; 31: 301). I do not feel that such advertisements conform to the ethical medical standards of a scientific journal. I fully understand that commercials are essential to finance the publication of a journal but advertisements of sex toys are totally out of character of a scientific journal.

N S Qureshi, MRCOG, DFFP

Specialist Registrar, Wrexham Maelor Hospital, Wrexham,UK.E-mail:nsq@doctors.net.uk

\section{Reply}

I was sorry to hear that Dr Qureshi objected to this advertisement. Many of the readers of this journal are necessarily involved in psychosexual therapy as part of their professional activities. In 2004, the journal published a special supplement about parenthood, emotional wellbeing and sexuality in which an advertisement for the firm Emotional Bliss appeared and was welcomed by the readership. Our readers are mainly concerned with contraception and reproductive health and, because of this, they treat more women than men. The commonest sexual problem in women is loss or lack of libido. Whatever a therapist's personal feelings about the use of sexual aids, it has been shown that they are a useful adjunct to treatment for sexual responsiveness in many women. The Journal's Editorial Board believes that enabling doctors and therapists to recommend a safe and discrete source for sexual aids assists the women that they are treating.

\section{Anne Szarewski, $\mathrm{PhD}$, FFFP}

Editor-in-Chief, Journal of Family Planning and Reproductive Health Care (on behalf of the Editorial Board)

The Journal wishes to apologise for any inconvenience or embarrassment caused to Dr Aileen Clarke that might have resulted from her name appearing in print as Aileen Clark within this article and on the contents page of the journal issue.

Community-based distribution and contraception usage in Iran, Jahanfar S, Ghodsi M, Shahpoorian F, Jamshidi R, J Fam Plann Reprod Health Care 2005; 31(3): 194-197

Unfortunately the details printed in the article for one of the contributing authors, Dr Zahra Ghodsy, were incorrect. The correct information is as follows: Dr Zahra Ghodsy, Azad University of Toyserkan, Hamedan, Iran. The Journal wishes to apologise unreservedly to Dr Ghodsy for any inconvenience and embarrassment this inadvertent error might have caused. 